\title{
circRNAs: Insight Into Their Role in Tumor-Associated Macrophages
}

\begin{abstract}
Saili Duan ${ }^{1,2,3,4 \dagger}$, Shan Wang ${ }^{1,2,3,4 \dagger}$, Tao Huang ${ }^{1,2,3,4}$, Junpu Wang ${ }^{1,2,3,4 *}$ and Xiaoqing Yuan ${ }^{5,6 *}$
${ }^{1}$ Department of Pathology, Xiangya Hospital, Central South University, Changsha, China, ${ }^{2}$ Xiangya School of Medicine, Central South University, Changsha, China, ${ }^{3}$ Department of Pathology, School of Basic Medicine, Central South University, Changsha City, China, ${ }^{4}$ National Clinical Research Center for Geriatric Disorders, Xiangya Hospital, Central South University, Changsha, China, ${ }^{5}$ Guangdong Provincial Key Laboratory of Malignant Tumor Epigenetics and Gene Regulation, Sun YatSen Memorial Hospital, Sun Yat-Sen University, Guangzhou, China, ${ }^{6}$ Breast Tumor Center, Sun Yat-Sen Memorial Hospital, Sun Yat-Sen University, Guangzhou, China
\end{abstract}

Currently, it is well known that the tumor microenvironment not only provides energy support for tumor growth but also regulates tumor signaling pathways and promotes the proliferation, invasion, metastasis, and drug resistance of tumor cells. The tumor microenvironment, especially the function and mechanism of tumor-associated macrophages (TAMs), has attracted great attention. TAMs are the most common immune cells in the tumor microenvironment and play a vital role in the occurrence and development of tumors. circular RNA (circRNA) is a unique, widespread, and stable form of non-coding RNA (ncRNA), but little is known about the role of circRNAs in TAMs or how TAMs affect circRNAs. In this review, we summarize the specific manifestations of circRNAs that affect the tumor-associated macrophages and play a significant role in tumor progression. This review helps improve our understanding of the association between circRNAs and TAMs, thereby promoting the development and progress of potential clinical targeted therapies.

Keywords: circRNA, TAMs, M2 macrophage, polarization, cancer

\section{INTRODUCTION}

With the continuous development of high-throughput sequencing, a class of covalently closed RNA molecules with extensiveness, diversity, stability, and evolutionary conservation has come into view, known as circular RNA (circRNA) $(1,2)$. circRNA has a unique covalently closed loop structure and a specific tertiary structure and exhibits tissue- and developmental stage-specific expression, which

\footnotetext{
Abbreviations: APCs, antigen-presenting cells; CAE, cancer-associated endothelial cells; CAFs, cancer-associated fibroblasts; circ-CDR1as, cerebellar degeneration-related 1 antisense; circ-PAIP2, circRNA poly(A) binding protein-interacting protein 2; circRNA, circular RNA; circ-ZNF609CSCs, circRNA zinc-finger protein 609; CSC, cancer stem cells; CRC, colorectal cancer; CTLA4, cytotoxic T-lymphocyte-associated protein 4; ECM, extracellular matrix; EcRNA, exonic circRNa; EGF, epithelial growth factor; EGFR, epidermal growth factor receptor; ElciRNA, exon-intron circRNA; ceRNA, competing endogenous RNA; HCC, hepatocellular carcinoma; HGF, hepatocyte growth factor; IL-10, interleukin 10; IL-17, interleukin 17; IL-23, interleukin 23; IRF, interferon regulatory factor; LPS, lipopolysaccharide stimulation; MBLs, mannose-binding lectins; MHC, major histocompatibility complex; miR, microRNA; ncRNA, non-coding RNA; NGS, next-generation sequencing; PD-L1, programmed death ligand 1; PDGF, platelet-derived growth factor; PGE2, prostaglandin 2; Pol II, polymerase II; RBPs, retinolbinding proteins; STAT, signal transducer and activator of transcription; TAMs, tumor-associated macrophages; TGF- $\beta 1$, transforming growth factor- $\beta 1$; TLR4, regulate toll-like receptor 4 ; TME, tumor microenvironment.
} 
plays an essential role in multiple cellular processes (3). Some circRNAs have been reported to be involved in tumor genesis, progression, and metastasis $(4,5)$, and circRNAs have been identified as important markers of various tumors (6-9). As a critical determinant of all stages of cancer development and progression, the tumor microenvironment (TME) is a complex ecosystem involving the coevolution of cancer cells and the surrounding matrix (10). A variety of cellular components in TME include immune cells [T cells, tumor-associated macrophages (TAMs), dendritic cells, mast cells, etc.], cancerassociated endothelial cells (CAE), cancer-associated fibroblasts (CAFs), and cancer stem cells $(11,12)$. Non-cellular counterparts include growth factors, cytokines, and extracellular matrix (ECM) (13). Other studies have shown that circRNAs play a variety of roles in the TME, promote or inhibit the immune system and angiogenesis, improve the permeability of endothelial cells, promote tumor metastasis, lead to ECM remodeling, and jointly support tumor progression $(14,15)$ - for example, CAFs can release circEIF3k under hypoxia, upregulate miR-214, and downregulate the programmed death ligand-1 (PD-L1) expression in colorectal cancer, thus inhibiting the progression of colorectal cancer (16). CAF-derived cytokines promote the progression and metastasis of hepatocellular carcinoma (HCC) by activating the circRNA-miRNA-mRNA axis in tumor cells (17). The high expression of cerebellar degeneration-related 1 antisense (circ-CDR1as) can enhance the penetration level of CAEs to promote tumor growth and metastasis (18). circRNAs may become the entry point of the entire ncRNA network, providing broad prospects for the clinical treatment of tumors (19).

Currently, circRNAs participate in the progression of tumorigenesis by acting on the TME and affecting the polarization of TAMs. However, the relationship and interactions of circRNAs and TAMs have not been systematically summarized. In this review, we will outline the specific manifestations of circRNAs affecting the tumor microenvironment as well as the latest findings suggesting that they participate in the metabolic reprogramming of tumor-associated macrophages and play an important role in tumor progression. Our review will improve the understanding of the relationship between circRNA and TAMs to promote the development and progress of potential clinical targeted therapies.

\section{circRNAs}

circRNAs are single-stranded RNAs with covalently closed circular structures with tissue/developmental stage-specific expression patterns (20-23), which are highly regulated by cis-acting elements and trans-acting factors (24-27). The covalently closed loops formed by circRNAs are produced by the back-splicing of the exon and/or intron sequences of the primary transcript and endow them with the inherent ability to resist the decay of extranuclear RNA (28). Back-splicing is catalyzed by the standard spliceosome mechanism, but protein factors and CIS-complementary sequences, especially Alu repeats, can regulate this process (29). Alu complementary-dependent base-pairing supports the connection of downstream splicing donor pairs with non-splicing upstream splicing receptors, and the contributed RNA is covalently closed (30). circRNAs exist in a wide range of species, ranging from viruses to mammals, and can function as transcriptional regulators, microRNA ( $\mathrm{miR}$ ) sponges, and protein templates $(6,31-33)$. Based on the diversity of source sequences, circRNAs can be divided into three categories: exonic circRNAs (EcRNA), exon-intron circRNAs (EIciRNAs), and circular intronic RNAs (ciRNAs) (8, 29, 34-36). However, a fourth tricRNA may be isolated, which corresponds to intronic circular tRNA (37). Most circRNAs are derived from premRNA, while a small portion of intron-derived circRNAs are derived from pre-tRNA $(36,38)$.

Many studies have shown that circRNA has several characteristics, namely (22):

(1) Abundance and diversity: thousands of different circRNAs have been identified in eukaryotes through RNA-seq technology, and the complexity of the circRNA production mechanism leads to its diversity $(29,39)$. The enrichment of circRNA can also be found in saliva and blood (22).

(2) Stability: a unique ring structure makes circRNA resistant to ribonuclease, without $5^{\prime}-3^{\prime}$ polarity and a polyadenylated tail, which results in higher stability than linear RNA (22).

(3) Conservation: circRNAs are highly conserved in different species (40).

(4) Specificity: circRNAs are usually specifically expressed in a tissue or developmental stage-specific manner $(8,41)$. The characteristics of circRNAs give them the following different functions:

(a) They have miRNA sponges, such as circRNA sexdetermining region Y (cir-SRY) (42). (b) They interact with proteins and their expression, such as retinol-binding proteins and mannose-binding lectins (43).

(c) They have translation templates, such as circRNA zincfinger protein 609 (circ-ZNF609) (44).

(d) They have transcription regulators, such as circRNA poly (A) binding protein-interacting protein 2 (circ-PAIP2) (45).

circRNAs are generated in the nucleus, but most of them are found in the cytoplasm - for example, circRNAs formed by exons are generally located in the cytoplasm (22), which suggests specific rules for circRNA transport or localization. Although most circRNAs are located primarily in the cytoplasm, ciRNAs and EIciRNAs are limited to the nucleus $(23,35,46)$, which means that their role is in nuclear events, such as transcriptional regulation. ciRNAs regulate the transcription of their parental genes by promoting the elongation of polymerase II. The binding of circRNAs to proteins may depend not only on nucleotide sequences but also on the different secondary or tertiary structures of circRNAs (47). Abnormally regulated circRNAs play a suppressive or carcinogenic role in the initiation and progression of cancer, affecting a number of cellular functions, such as the maintenance of proliferation signals, promotion of cell migration and invasion, resistance to apoptosis, and induction of angiogenesis $(48,49)$. Meanwhile, circRNAs play an important regulatory role in diseases by interacting with disease-related miRNAs (50). Studies have shown that circRNAs are helpful for the treatment of osteoporosis, which is related to the differentiation of osteoclasts (51).

circRNAs, with a closed-loop structure and high stability, are gene expression regulators that play a variety of regulatory roles in 
transcription, splicing, and chromatin interactions (52). The differences in the formation process and shape of the four circRNAs as well as the characteristics and functions of circRNAs are shown in Figure 1 (53). circRNAs exhibit inherent conserved and environmental resistance stability due to their circular structure, presence in blood and peripheral tissues, and coexistence with exosomes and may be considered as potential biomarkers or therapeutic targets for a number of immune diseases (54). Most circRNA translation products have an impact on cancer progression or inhibition $(49,55)$, which leads to abnormal expression in various types of cancer (28), including colorectal cancer (56), hepatocellular carcinoma $(5,57,58)$, gastric cancer $(59$, $60)$, acute promyelocytic leukemia (61), and breast cancer $(62,63)$. Listed in Table $\mathbf{1}$ is the relationship between some circRNAs and tumors, suggesting that circRNAs are mainly related to inflammatory responses, including the interaction between cytokines and chemokines, and are a potential disease marker that can be used as promising biomarkers for diagnosis, providing a new therapeutic target for tumor treatment $(65,66)$.

\section{TAMs}

A tumor has a highly heterogeneous structure. Tumor cells interact with a variety of cells and factors, including immune cells and immune factors, to form a complex tumor immune microenvironment (67). The TME is a complex environment where tumor cells coexist with immune cells and other cells, blood vessels, signaling molecules, and the ECM and is the place where the immune system interacts with tumor cells (68). Exosomes are a component of the TME (69); they act as effective signaling molecules between cancer cells and surrounding cells that make up the TME $(9,70)$. Studies have found that circRNA molecules can be transferred to exosomes and are more abundant in exosomes than in cells, suggesting that they may be promising cancer biomarkers (9). Meanwhile, the TME can actively reprogram macrophage metabolism through the direct exchange of metabolites, cytokines, and other signaling mediators in cancer (71).

Macrophages are composed of many cell types with complex and delicate regulatory networks. The type, density, and location of macrophages, as well as other inflammatory infiltrates, have good

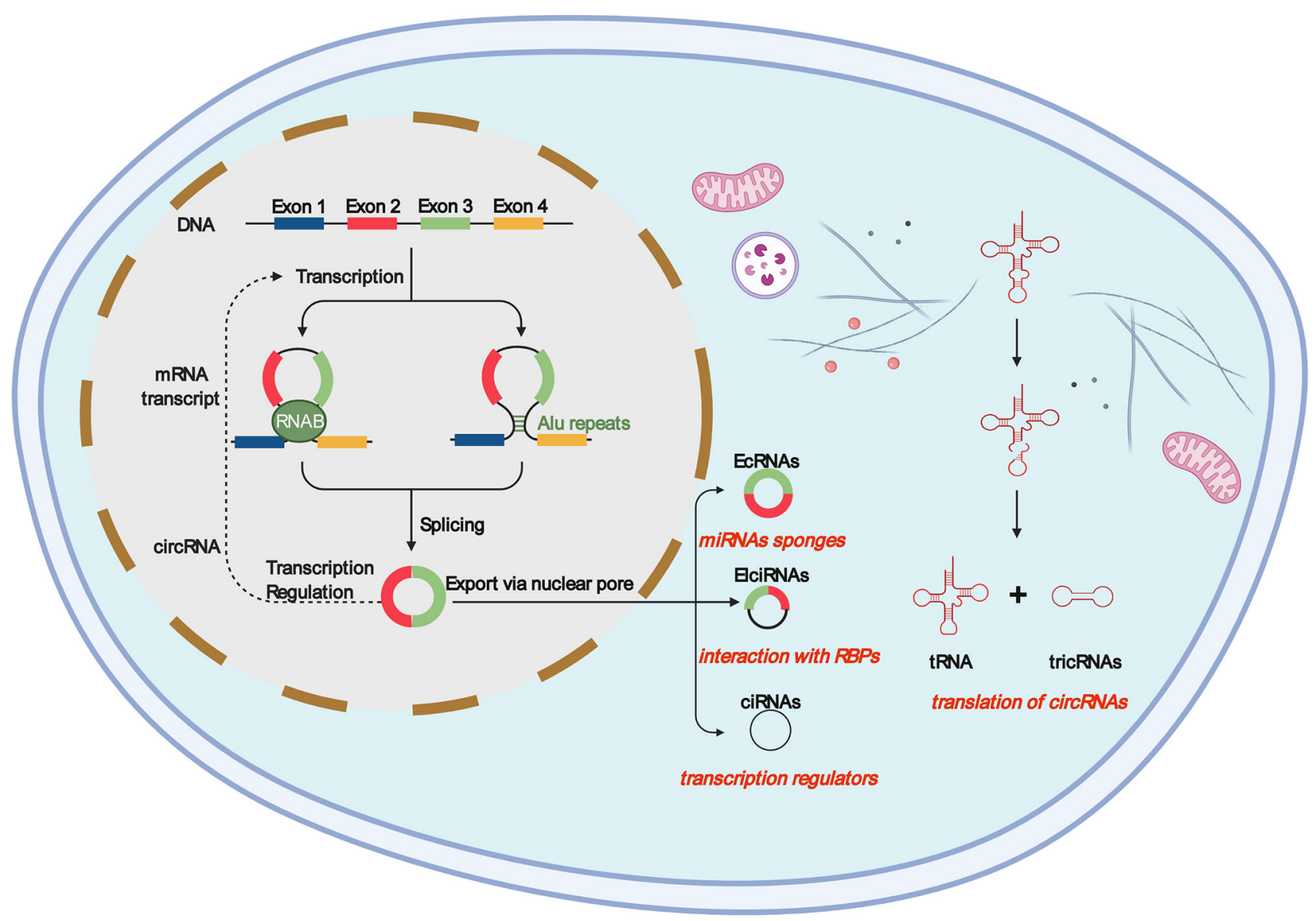

FIGURE 1 | Most ecircRNAs are primarily produced from two or three exons of reverse splicing, in which the $3^{\prime}$ splicing donor of the pre-mRNA is covalent to the 5' splicing receptor. Intron circular RNAs include circular intron RNAs (ciRNAs), excision of group I introns, excision of group II introns, excision of lariat introns, and excision of tRNA introns. Exon-intron circular RNA is a circular RNA in which exons and introns exist simultaneously. Internal repetitive sequences may play an important role in its generation, possibly similar to ecircRNAs. Intergenomic circRNAs contain two intron circRNAs, flanked by GT-AC splicing signals, which act as splicing donors and acceptors of circRNAs and form a complete circRNA. The resulting intron ends are joined by RtcB ligase to form a stable circRNA, named tricRNA. 
TABLE 1 | Some circRNA types in cancers.

\begin{tabular}{|c|c|c|c|c|c|c|}
\hline Types & Expression & Cancers & $\begin{array}{c}\text { miRNA } \\
\text { sponges }\end{array}$ & Roles & Influence & References \\
\hline circMTO1 & $\begin{array}{l}\text { Under- } \\
\text { expressed }\end{array}$ & $\begin{array}{l}\text { Hepatocellular } \\
\text { carcinoma }\end{array}$ & miR-9 & $\begin{array}{l}\text { Tumor } \\
\text { suppressor }\end{array}$ & It affects the expression of downstream P21 protein & $(57)$ \\
\hline $\begin{array}{l}\text { circRNA } \\
\text { cSMARCA5 }\end{array}$ & Downregulated & $\begin{array}{l}\text { Hepatocellular } \\
\text { carcinoma }\end{array}$ & $\begin{array}{l}\text { miR-181b- } \\
5 p \\
\text { miR-17-3p }\end{array}$ & $\begin{array}{l}\text { Tumor } \\
\text { suppressor }\end{array}$ & $\begin{array}{l}\text { It inhibits the proliferation and metastasis of the cancer by } \\
\text { regulating TIMP3 expression }\end{array}$ & $(5,58)$ \\
\hline $\begin{array}{l}\text { circRNA circ- } \\
\text { Ccnb1 }\end{array}$ & Downregulated & Breast cancer & / & $\begin{array}{l}\text { Cell death } \\
\text { agent }\end{array}$ & It results in the induction of cell death in cancer & $(62)$ \\
\hline circGFRA1 & Upregulated & Breast cancer & $\begin{array}{l}\text { miR-34a } \\
\text { ceRNA }\end{array}$ & $\begin{array}{l}\text { Tumor } \\
\text { suppressor }\end{array}$ & It regulates GFRA1 expression & (63) \\
\hline $\begin{array}{l}\text { circRNA f- } \\
\text { circM9 }\end{array}$ & Upregulated & $\begin{array}{l}\text { Acute promyelocytic } \\
\text { leukemia }\end{array}$ & / & $\begin{array}{l}\text { Proto- } \\
\text { oncogene }\end{array}$ & It contributes to cellular transformation in cancer & $(61)$ \\
\hline $\begin{array}{l}\text { circRNA } \\
\text { circ0006916 }\end{array}$ & Downregulated & Lung cancer & miR-522-3p & $\begin{array}{l}\text { Tumor } \\
\text { suppressor }\end{array}$ & $\begin{array}{l}\text { It inhibits cell proliferation by slowing down the cell cycle } \\
\text { process }\end{array}$ & $(64)$ \\
\hline CiRS-7 & Upregulated & Gastric cancer & $\mathrm{miR}-7$ & $\begin{array}{l}\text { Tumor } \\
\text { suppressor }\end{array}$ & $\begin{array}{l}\text { It antagonizes the miR-7-mediated PTEN/PI3K/AKT pathway in } \\
\text { gastric cancer }\end{array}$ & (59) \\
\hline circ-ITCH & Upregulated & Gastric cancer & $\begin{array}{l}\text { MiR-199a- } \\
5 p\end{array}$ & $\begin{array}{l}\text { Tumor } \\
\text { suppressor }\end{array}$ & It affects the EMT process of gastric cancer & $(60)$ \\
\hline circCCDC66 & Upregulated & Colorectal cancer & $\begin{array}{l}\text { miR-33b } \\
\text { miR-93 } \\
\text { miR-185 }\end{array}$ & $\begin{array}{l}\text { Proto- } \\
\text { oncogene }\end{array}$ & It is associated with poor cancer prognosis & $(56)$ \\
\hline
\end{tabular}

prognostic value in various cancer types (72-74). Macrophages are key mediators of tissue homeostasis, while tumors upset this balance; macrophages can even become drivers of metastasis (72, 75). Macrophages are specialized phagocytes that differentiate from circulating classical monocytes after extravasation into tissues (76, 77) and express both activating and inhibiting receptors in the phagocytosis of opsonic or apoptotic cells (78). Macrophages can engulf a large number of pathogens and kill bacteria in cells (79-81). In addition to directly killing tumor cells, macrophages also serve as specialized antigen-presenting cells, which can present tumor cellderived antigens on major histocompatibility complex (MHC) class I (82) and class II (83) molecules, thereby activating endogenous antitumor $\mathrm{T}$ cell responses, amplifying the therapeutic effect and reducing the risk of tumor cell escape due to antigen loss (84-86). TAMs are derived from bone marrow-derived monocytes and tissue macrophages that are recruited into and fill the TME, promoting the spread and diffusion of cancer cells (87-90). TAMs are key cells that generate immunosuppressive tumor microenvironments by producing cytokines, chemokines, and growth factors and triggering $\mathrm{T}$ cells to release inhibitory immune checkpoint proteins. TAMs can directly help tumor cells migrate through the paracrine ring between macrophages and tumor cells, which involves macrophages secreting epithelial growth factor (EGF) family ligands and tumor cells secreting CSF1, to improve the invasive characteristics of tumor cells (91).

Consistent with macrophages, TAMs are also highly plastic (92) and adapt to microenvironmental changes by regulating cell metabolism and reprogramming phenotypes (93, 94). TAMs enhance tumor progression by promoting genetic instability, angiogenesis, fibrosis, immunosuppression, lymphocyte rejection, invasion, and metastasis and promote the inflammatory environment by secreting cytokines, such as interleukin-17 (IL17) and interleukin-23 (IL-23) $(95,96)$. Many studies have shown that TAM infiltration is closely related to tumor cell proliferation and can express a variety of cytokines that stimulate tumor cell proliferation and survival, including EGF, platelet-derived growth factor, transforming growth factor- $\beta 1$, hepatocyte growth factor, and epidermal growth factor receptor $(97,98)$. Figure 2 shows that, once monocytes from peripheral blood are recruited into the tumor, the tumor environment rapidly promotes their differentiation into TAMs (96). Initially, monocytes and macrophages are recruited to the site of tumorigenesis. Under the guidance of different microenvironmental signals, macrophages can differentiate into two functional phenotypes, namely, classical activated macrophages (M1) and alternately activated macrophages (M2). In contrast to the antitumor effects of M1, M2 has antiinflammatory and tumorigenic properties. M2 TAMs are predominant in progressive tumors and are important regulatory cells in the TME response $(99,100)$. The major event in the tumor microenvironment is the polarization of macrophages into the tumor-suppressor M1 or tumor-promoting M2 macrophages. Although there is considerable evidence that TAMs are predominantly M2-like macrophages, the mechanisms by which TAMs polarize into M1 and M2 macrophages remain unclear (101). TAMs exhibit the patterns of M1 and M2 macrophages, but these cells are known to have transcriptional profiles different from those of M1 or M2 macrophages (102). However, it is certain that TAMs are related to the occurrence and development of various tumors, such as breast cancer, prostate cancer, glioma, lymphoma, bladder cancer, lung cancer, cervical cancer, and melanoma (103-105). TAMs, which are abundant in most types of malignancies, can promote tumor angiogenesis, allowing cancer cells to escape from the tumor into the circulation and inhibit anti-tumor immune mechanisms $(106,107)$. Some studies have shown that CSF1, IL-4, IL-13, and IL-10 can promote the polarization of M1-like TAMs to M2-like TAMs in the TME (102). Under specific conditions, the transformation of M2-like TAMs into M1-like TAMs may lead to tumor regression (108). By releasing pro-inflammatory molecules, 


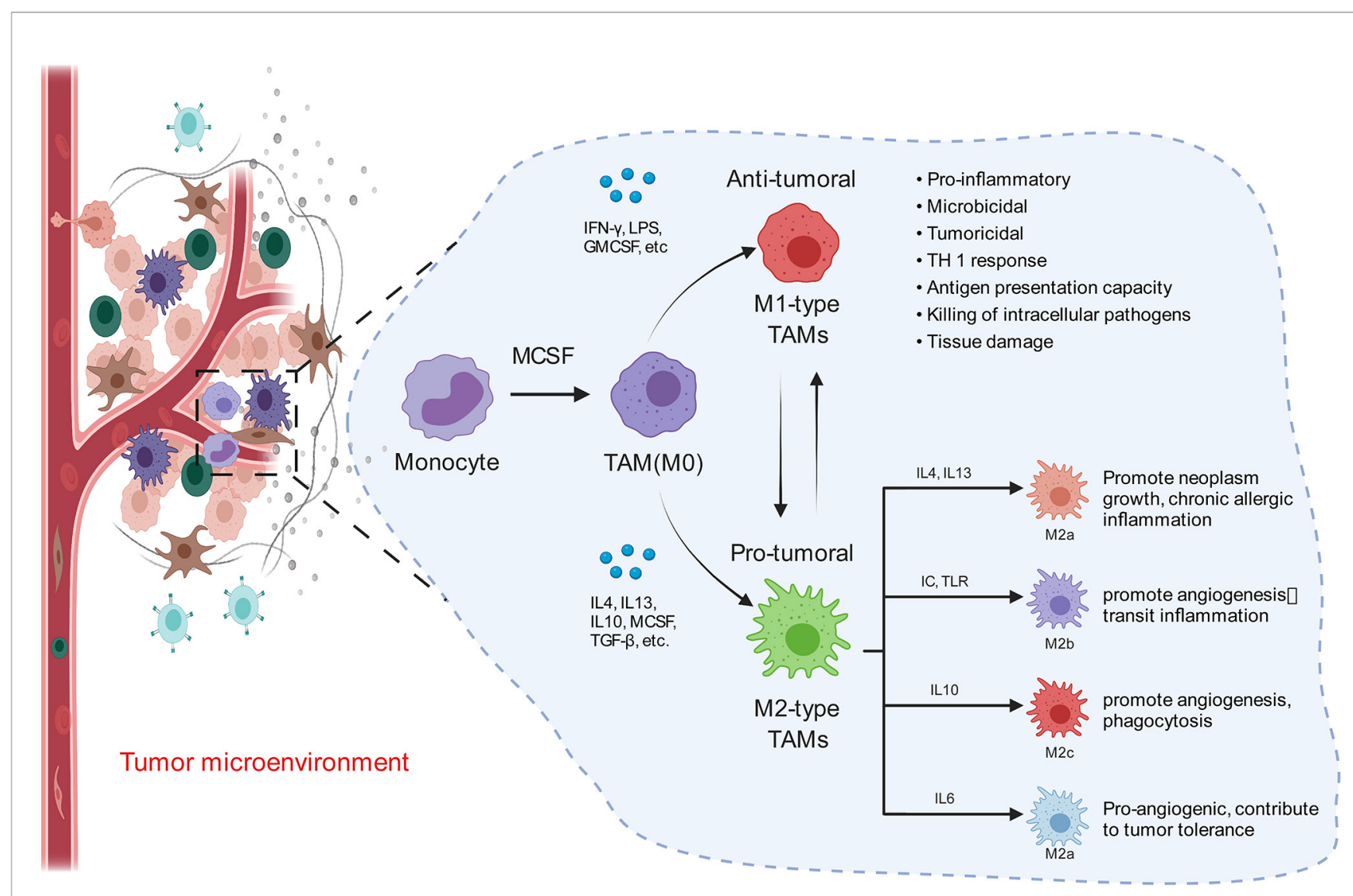

FIGURE 2 | Macrophages in the tumor microenvironment become tumor-associated macrophages (M0) once exposed to tumor substances (MCSF), and M0 can differentiate into M1 and M2. When activated by interferon - $\gamma$ and lipopolysaccharides, M1 macrophages show bactericidal activity and express high levels of CD86, inducible nitric oxide synthase, and pro-inflammatory cytokines, such as interleukin (IL-6), IL-12, IL-23, and tumor necrosis factor. M2 macrophages are activated by Th2 cytokines IL-4 and IL-13 as well as various parasite-related signals, which can be divided into four subtypes (M2a, M2b, M2c, and M2d). They are mainly involved in inhibiting type I inflammation and promoting tissue repair and healing responses.

such as TNF- $\alpha$ and IFN- $\gamma$, activating TLR, and reducing antiinflammatory factors (such as ARG1, TGF- $\beta$, and IL10), M1-like TAMs can promote the inflammatory response and antitumor activity of the TME (109). TAMs can antagonize, enhance, or mediate the antitumor effects of cytotoxic agents, tumor irradiation, antiangiogenic/vascular injury agents, and checkpoint inhibitors (73, 110-113).

\section{THE RELATIONSHIP BETWEEN circRNAS AND MACROPHAGE POLARIZATION}

In primary tumors, TAMs have an M1-like phenotype and can eliminate certain immunogenic tumor cells (114). However, the TME can induce the M2-like polarization of TAMs, which is the cause of the formation of primary carcinoma $(111,115)$. Studies have demonstrated the relationship between circRNAs and macrophages-for example, circASAP1 can act as a competing endogenous RNA (ceRNA) of miR-326 and miR-532-5p to mediate TAM infiltration, and circRNA-CDR1as may be crucial for tumor tissue immunity and cell penetration, such as $\mathrm{CD} 8^{+} \mathrm{T}$ cells, activated natural killer (NK) cells, and M2 macrophages (116). circ-ASAP1 can mediate TAM osmosis by regulating the miR-326/miR-532-5PCSF-1 pathway (117). There is no specific mechanism elucidated in this respect, which suggests that the next step is to study how circRNAs interact with tumor-associated macrophages. Studies have shown that circRNAs can regulate macrophage differentiation and polarization, while the pathways regulating macrophage polarization are not completely clear. Several molecules are involved in this process (Figure 3), such as interferon regulatory factor (IRF) and signal transducer and activator of transcription (STAT) $(118,119)$. Lipopolysaccharide stimulation (LPS) stimulates M1 macrophages by inducing STAT1- $\alpha$ and STAT1- $\beta$ and interacting with the receptor TLR-4 (120). circPPM1F can play an active role in the LPS-induced activation of M1 macrophages through the circPPM1F-HUr-PPM1F-NF- $\mathrm{BB}$ axis (121), and circCdy can promote M1 polarization by inhibiting the entry of IRF4 into the nucleus (122). CSF-1, IL-4, IL-10, TGF- $\beta$, and IL-13 are conducive to the polarization of the M2 subgroup $(123,124)$. The overexpression of has-circ-0005567 inhibits the polarization of M1 macrophages and promotes the polarization of M2 macrophages (125). Compared with M2-type macrophages, circRNA-003780, circRNA-010056, and 


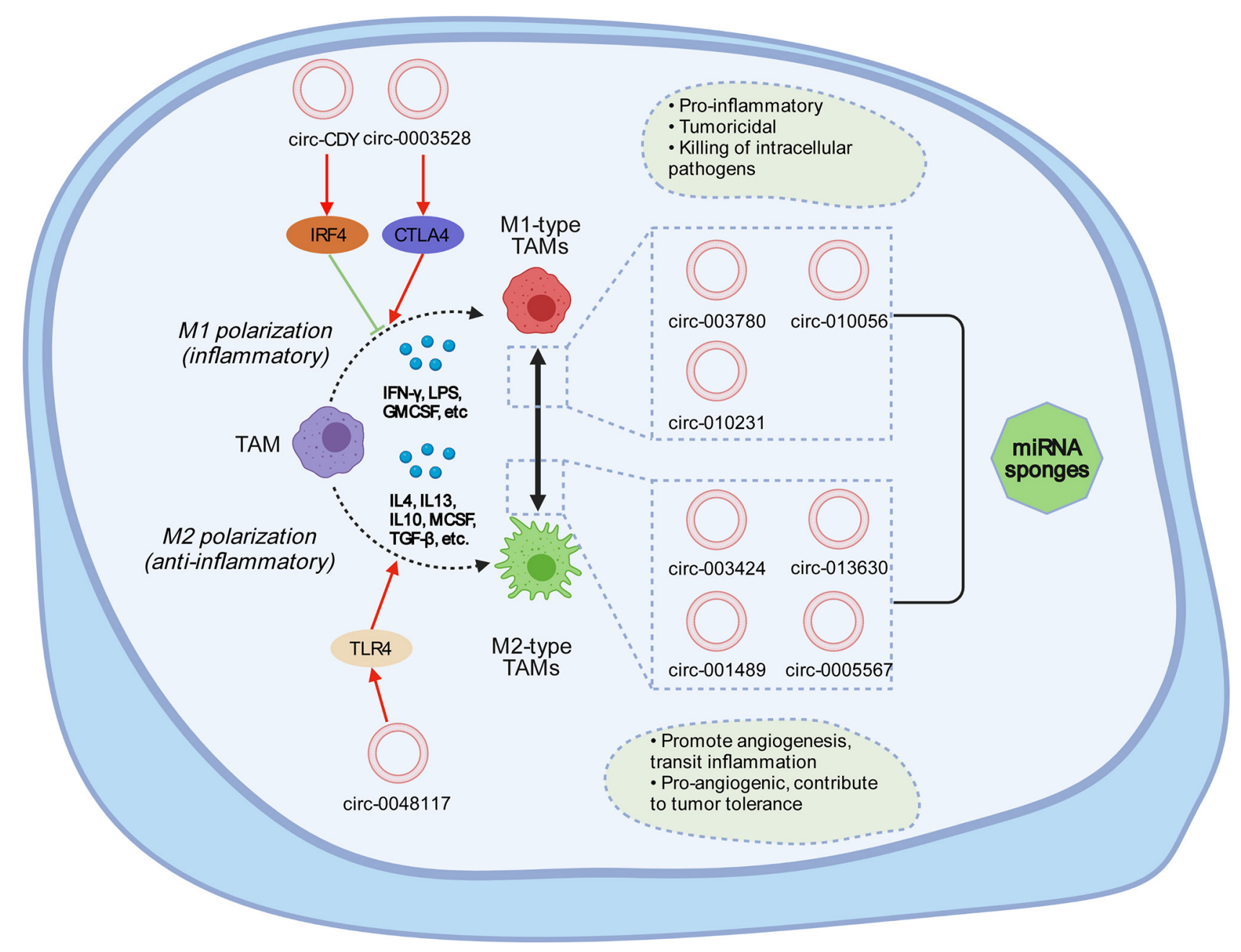

FIGURE 3 | Tumor-associated macrophages can usually be divided into M1 type and M2 type. M1 macrophages are generally activated through interferon- $\gamma$ and lipopolysaccharides, which mainly secrete pro-inflammatory factors and play a vital role in the early stage of inflammation. M2 macrophages are activated by Th2 cytokines, such as IL-4, IL-13, and the immune complex, express and inhibit the inflammatory factors, and play a role in inhibiting inflammatory response and tissue repair. circRNA can affect the mutual transformation between M1 and M2. circRNA-0003528 induces M1 macrophage polarization by activating CTLA4. circRNA0048117 promotes the polarization of M1 to M2 macrophages by promoting the expression of TLR4. circ-Cdy can affect M1 polarization through IRF4. In M1 polarization, the expressions of circ-003780, circ-010056, and circ-010231 are upregulated, while the expressions of circ-003424, circ-013630, and circ-001489 are downregulated; the opposite is true for M2 polarization. circ-0005567 can inhibit M1 polarization and promote M2 polarization.

circRNA-010231 are upregulated in M1 macrophages. However, the expression of circRNA-003424, circRNA-013630, circRNA-001489, and circRNA-018127 is downregulated (126). Studies have shown that, in general, M1 is expressed in bones, the brain, and other adult tissues, and M2 is expressed in embryonic development stages, undifferentiated tissues, and tumors (127). circ-0048117 can regulate toll-like receptor 4 (TLR4) by acting as an miR-140 sponge to promote the polarization of M2 macrophages. Studies have confirmed that the activation of TLR4 on the surface of macrophages plays an important role in macrophage differentiation (128). TLR4 is strongly expressed in lung cancer TAMs and promotes the transformation of TAMs to M2-type macrophages by promoting the oxidative phosphatizing process in mitochondrial metabolism and inhibiting the glycolysis pathway
(129). circRNA-0003528 promotes tuberculosis-associated macrophage polarization by upregulating the expression of cytotoxic T-lymphocyte-associated protein 4 (130).

Although most studies have found that circRNAs are more closely related to M2 polarization, the specific mechanism between circRNAs and M2 is not clear. Under the influence of tumorderived factors, TAMs can secrete a series of cytokines, including IL10 , TGF- $\beta$, and prostaglandin 2 (PGE2), to further inhibit T cellmediated immune responses and establish a self-proliferative immunosuppressive TME $(72,74)$. These cytokines can also affect circRNA expression. Accordingly, interleukin-10 (IL-10) can also inhibit the function of a variety of immune cells and the expression of anti-inflammatory macrophages; additionally, IL-10 can induce Tregs. Besides these, the abnormally expressed extracellular 
circRNA may induce Treg cells and interact directly with immune factors to mediate immune activity and facilitate intercellular communication $(131,132)$. IL-10 produced by TAMs can inhibit the function of antigen-presenting cells and then block the function of $\mathrm{T}$ cell effects, such as cytotoxicity, to inactivate the anti-tumor response, which leads to the downregulation of circRNAs related to the tumor response, thus promoting tumor growth (133). It was found that the transformation from M2-like TAMs to M1-like TAMs can lead to tumor regression under specific conditions (134). The mutual regulation between M1-like and M2-like TAMs is achieved by signal axes, such as STAT1/STAT6 and IRF5/IRF4, which are very important for the occurrence, development, and cessation of tumor inflammation (135). This may be a potential target for the regulation of M1-like and M2-like TAM transformation in clinical cancer immunotherapy. Promoting the conversion of M2 macrophages to the M1 phenotype can become a tumor treatment method (136).

Complex interactions exist between circRNAs and key counterparts in the TME (137), which can affect a variety of physiological and pathological activities, including tumor angiogenesis $(138,139)$. CAE is arranged on the inner surface of tumor blood vessels and lymphatic vessels, which can support angiogenesis and tumor neovascularization (140), while circCDRlas is positively correlated with the CAE infiltration level (18). Endothelial cells are the key to tumor angiogenesis, and the effect of circRNA on endothelial cells can affect tumor progression $(141,142)$-for example, circ-IAR can destroy the tight junctions between endothelial cells, increase the permeability of vascular endothelial cells, and promote tumor metastasis (143). Some circRNAs can induce the expression of PD-L1 in the TME and mediate the regulation of tumor immunity-for example, the upregulation of PD-L1 mediated by has-circ-0020397 can lead to the inhibition of apoptosis and the acquisition of tumor immune escape in the TME (144). In short, tumor development is generally related to M2 polarization, and circRNA is also more closely related to M2 polarization and can act with related factors in the TME. The transformation from M2 to M1 can promote tumor regression, which suggests that we can further study key targeted circRNAs to inhibit M2 polarization and promote the transformation from M2 to $\mathrm{M} 1$ to treat tumors.

\section{circRNAs ARE ASSOCIATED WITH TAMs IN DIFFERENT CANCERS}

TAMs infiltrate most solid tumors in large numbers and contribute to tumor progression by stimulating proliferation, angiogenesis, and metastasis and providing anti-tumor immune barriers. Co-existing with circRNAs in the TME, TAMs may establish and reshape the extracellular matrix structure by allowing tumor cells to invade through the TME. circRNAs enable TAMs to interact with tumor cells or other stromal cells by secreting growth factors, cytokines, and chemokines $(72,76)$. Signals from tumor cells, lymphocytes, and stromal cells affect TAM function and diversity as well as the corresponding changes in circRNA expression $(145,146)$. circRNAs play a key role in the development and progression of human cancers such as lung, liver, breast, and colon cancers. Because of the large number of circRNAs, their functions may be complex and different from each other, so the functions and mechanisms of most circRNAs, such as has-circ-0014235, have not been fully identified, and little is known about the existence or effect of circRNA modification. The specific interactions between circRNAs and TAMs are also unknown. In TAMs, circPTK2 is mainly expressed in the tumor invasion frontier (M1-rich area) and stroma (M2-rich area). In contrast, circHIPK3 is mainly expressed in M2, located in the tumor nest and surrounding tumor invasion, suggesting that circRNA is closely related to tumor pathology and prognosis (147). Meanwhile, circRNAs have been found to be enriched in exosomes (4). circRNAs can specifically bind to tumor-specific miRNAs or mRNAs in exons and can be used as new tumor antigens to regulate the immune response (141). Some circRNAs can be detected in exosomes from the serum, urine, and tumors. Exosome circRNAs may be involved in cell growth, angiogenesis, epithelialmesenchymal transformation, and targeted therapy $(148,149)$ for example, circFBLIM1 carried by serum exosomes can be transferred to HCC cells, thereby promoting disease progression and suggesting that circRNA may be a biomarker of various diseases (150). In colorectal cancer, the exons secreted by M2 macrophages highly express miR-21-5p and miR-155-5p to regulate the migration and invasion of colorectal cancer cells (151). circBACH1 (has-circ-0061395) is significantly upregulated in HCC tissues, and p27 inhibition is regulated by HUR, which reduces circ$\mathrm{BACH} 1$ to inhibit the proliferation and increase the apoptosis of HCC cells (152). Studies have shown that circASAP1 promotes the proliferation and invasion of HCC cells by regulating miR-326/ miR-532-5p-MAPK1 signaling and regulates the infiltration of tumor-associated macrophages by regulating the $\mathrm{miR}-326 / \mathrm{miR}$ 532-5P-CSF-1 pathway (117).

High TAM infiltration is associated with a low overall survival rate in breast, gastric, oral, ovarian, bladder, and thyroid cancers but is not associated with low overall survival in colorectal cancer (CRC) (153). In bladder cancer, circPTK2 promotes the proliferation and migration of bladder tumor cells through the interaction of M2 tumor-associated macrophages (154), while circHIPK3 has been found in CRC by activating the downstream Bcl/Beclin 1 signaling pathway in the TME, thus promoting the growth and differentiation of TAMs (155). circRNA-002178 can act as a ceRNA and induce T cell depletion in lung adenocarcinoma by promoting PD-L1/PD1 expression in cancer cells with spongy miR-34 (156), which affects the polarization process of tumor-associated macrophages, as shown in Figure 3. Mutated p53 cancer cells can be re-transformed from macrophages to TAM through miR-1246 (157), which is beneficial for anti-inflammatory immunosuppression and the increased activities of TGF- $\beta$, while it also affects the expression of related circRNAs (158).

In TAMs, circ-0061395 competitively combines with miR-877-5p to improve the expression of PIK3R3 and promote the degree of malignancy of HCC cells. The inhibition of circWHSC1 in vitro can inhibit the proliferation and metastasis of HCC cells and inhibit tumorigenesis in vivo (159). Other studies have shown that circWHSC1, as a sponge for miR-142-3p, directly targets HOXA1, which inhibits the polarization of TAMs, while inhibiting miR-142- 
$3 p$ can improve the effects of circWHSC1 gene knockdown on the proliferation and metastasis of HCC cells. The overexpression of miR-142-3p inhibits the growth and motility of HCC cells, and the elevation of HOXA1 reverses this effect (160). The overexpression of circMCTP2 in gastric cancer can restore MTMR3 expression in gastric cancer cells to cisplatin through sponging miR-99a-5p, which also affects the process of macrophage reprogramming TAMs (161). Other studies have also shown that exosomal circRNA can promote cell growth and inhibit DNA damage (162). Experimental results have shown that circPPM1F can accelerate the activation of M1 macrophages and accelerate the apoptosis of islet cells in diabetic mice (121). Therefore, further studies of exosomal circRNAs will provide a new method for the diagnosis and targeted treatment of many diseases.

\section{CONCLUSION AND PROSPECT ON circRNAs AND TAMs}

With the development of next-generation sequencing technology, an increasing number of circRNAs have been discovered. circRNAs are a novel class of non-coding endogenous RNAs with closed-loop characteristics. At present, there is no evidence that circRNAs are directly related to the differentiation of tumor-associated macrophages, but some studies have shown that they can be transformed into endogenous RNA to participate in the differentiation process. However, not all circRNAs are positively correlated with tumor-associated macrophages, and the specific correlation between them deserves further study. In general, M1 macrophages promote inflammatory responses against invading pathogens and tumor cells, while M2 macrophages tend to exhibit an immunosuppressive phenotype that is conducive to tissue repair and tumor progression. The abundance of TAMs in tumors is often related to the acquisition of tumor-specific pathological features, such as immunosuppression, neovascularization, invasiveness, metastasis, and poor response to treatment, which indirectly suggests that TAMs may have a tumor-promoting function. TAMs may affect the expression of circRNAs in various cancers, such as lung cancer, liver cancer, colon cancer, and gastric cancer.

Tumor-associated macrophages, especially those that infiltrate tumor tissues, secrete various cytokines according to their polarity and play an important role in the occurrence, invasion, and metastasis of tumors. circRNAs, on the other hand, can specifically adsorb miRNAs to be used as competitive endogenous RNAs. By enhancing exon expression, circRNAs interact with the TME to establish an immunosuppressive environment and promote tumor cell proliferation, anti-apoptosis, invasion, and migration. Unfortunately, the cause and function of circRNA are not entirely clear; this is also true for the role of the specific mechanism between circRNAs and TAMs. However, previous studies have shown that there is little correlation between the two. Further research will help us delve into the role of circRNA and TAMs in tumor growth. The dynamic balance and interaction between TAMs and tumor cells play an important role in the occurrence and development of tumors. circRNAs can also affect TAM differentiation by influencing the TME, thus further affecting tumor growth and development. It was found that the expression of circRNAs in tumor tissues is not absolutely upregulated or downregulated; it may be upregulated in lung cancer but downregulated in breast cancer. Such contradictions make it difficult to connect the polarization of TAMs with the expression of circRNAs, but they show a correlation. Studies on the relationship between circRNAs and TAMs are still at a superficial stage, and there are not enough studies to prove a clear logical relationship between them. circRNAs have many small molecular subtypes, and the TAM polarization process involves many small molecular substances. Perhaps an algorithm can be developed to study the pairwise collocation or mixed collocation between the two to further reveal the relationship between them; this is a direction for future research. Further studies on the relationship between circRNAs and TAMs can help elucidate the role of circRNAs in the nervous system, cancer development, innate immune response, and other biological environments and diseases. circRNA is expected to become a new tumor marker and potential target, providing a new direction for tumor diagnosis and targeted therapy.

\section{AUTHOR CONTRIBUTIONS}

All authors listed have made a substantial, direct, and intellectual contribution to the work and approved it for publication.

\section{FUNDING}

This work was partially supported by the National Natural Science Foundation of China (project no. 81602167), the Hunan Provincial Natural Science Foundation of China (project no. 2017JJ3494 and 2021JJ31100), and the Science and Technology Program Foundation of Changsha City (project no. kq2004085). This work was also supported in part by the National Natural Science Foundation of China (project no. 81803636 to XY) and Guangdong Basic and Applied Basic Research Foundation (project no. 2018A0303130329 to XY).

\section{REFERENCES}

1. Chen LL, Yang L. Regulation of CircRNA Biogenesis. RNA Biol (2015) 12:381-8. doi: 10.1080/15476286.2015.1020271

2. Zhang L, Hou C, Chen C, Guo Y, Yuan W, Yin D, et al. The Role of N(6)Methyladenosine (M(6)a) Modification in the Regulation of CircRNAs. Mol Cancer (2020) 19:105. doi: 10.1186/s12943-020-01224-3

3. Du WW, Zhang C, Yang W, Yong T, Awan FM, Yang BB. Identifying and Characterizing CircRNA-Protein Interaction. Theranostics (2017) 7:418391. doi: 10.7150/thno.21299

4. Wang Y, Liu J, Ma J, Sun T, Zhou Q, Wang W, et al. Exosomal CircRNAs: Biogenesis, Effect and Application in Human Diseases. Mol Cancer (2019) 18:116. doi: 10.1186/s12943-019-1041-Z

5. Yu J, Xu QG, Wang ZG, Yang Y, Zhang L, Ma JZ, et al. Circular RNA Csmarca5 Inhibits Growth and Metastasis in Hepatocellular Carcinoma. J Hepatol (2018) 68:1214-27. doi: 10.1016/j.jhep.2018.01.012

6. Hansen TB, Kjems J, Damgaard CK. Circular RNA and Mir-7 in Cancer. Cancer Res (2013) 73:5609-12. doi: 10.1158/0008-5472.CAN-13-1568

7. Wang R, Zhang S, Chen X, Li N, Li J, Jia R, et al. Circnt5e Acts as a Sponge of MiR-422a to Promote Glioblastoma Tumorigenesis. 
Cancer Res (2018) 78:4812-25. doi: 10.1158/0008-5472.CAN-180532

8. Salzman J, Chen RE, Olsen MN, Wang PL, Brown PO. Cell-Type Specific Features of Circular RNA Expression. PloS Genet (2013) 9:e1003777. doi: 10.1371/journal.pgen.1003777

9. Zhao W, Dong M, Pan J, Wang Y, Zhou J, Ma J, et al. Circular Rnas: A Novel Target Among Non-Coding RNAs With Potential Roles in Malignant Tumors (Review). Mol Med Rep (2019) 20:3463-74. doi: 10.3892/ mmr.2019.10637

10. Belli C, Trapani D, Viale G, D’Amico P, Duso BA, Della Vigna P, et al. Targeting the Microenvironment in Solid Tumors. Cancer Treat Rev (2018) 65:22-32. doi: 10.1016/j.ctrv.2018.02.004

11. Quail DF, Joyce JA. Microenvironmental Regulation of Tumor Progression and Metastasis. Nat Med (2013) 19:1423-37. doi: 10.1038/nm.3394

12. Ringuette Goulet C, Bernard G, Tremblay S, Chabaud S, Bolduc S, Pouliot F. Exosomes Induce Fibroblast Differentiation Into Cancer-Associated Fibroblasts Through Tgf $\beta$ Signaling. Mol Cancer Res: MCR (2018) 16:1196-204. doi: 10.1158/1541-7786.MCR-17-0784

13. Natua S, Dhamdhere SG, Mutnuru SA, Shukla S. Interplay Within Tumor Microenvironment Orchestrates Neoplastic RNA Metabolism and Transcriptome Diversity. Wiley Interdisciplinary Reviews. RNA (2021) 2021:e1676. doi: 10.1002/wrna.1676

14. Zhang Q, Wang W, Zhou Q, Chen C, Yuan W, Liu J, et al. Roles of CircRNAs in the Tumour Microenvironment. Mol Cancer (2020) 19:14. doi: 10.1186/s12943-019-1125-9

15. Chen LL. The Expanding Regulatory Mechanisms and Cellular Functions of Circular RNAs. Nat Rev Mol Cell Biol (2020) 21:475-90. doi: 10.1038/ s41580-020-0243-y

16. Yang K, Zhang J, Bao C. Exosomal Circeif3k From Cancer-Associated Fibroblast Promotes Colorectal Cancer (CRC) Progression via MiR-214/ PD-L1 Axis. BMC Cancer (2021) 21:933. doi: 10.1186/s12885-021-08669-9

17. Liu G, Sun J, Yang ZF, Zhou C, Zhou PY, Guan RY, et al. Cancer-Associated Fibroblast-Derived CXCL11 Modulates Hepatocellular Carcinoma Cell Migration and Tumor Metastasis Through the Circubap2/Mir-4756/IFIT1/ 3 Axis. Cell Death Dis (2021) 12:260. doi: 10.1038/s41419-021-03545-7

18. Zou Y, Zheng S, Deng X, Yang A, Xie X, Tang H, et al. The Role of Circular RNA CDRlas/Cirs-7 in Regulating Tumor Microenvironment: A PanCancer Analysis. Biomolecules (2019) 9:429. doi: 10.3390/biom9090429

19. Yu T, Wang Y, Fan Y, Fang N, Wang T, Xu T, et al. Circrnas in Cancer Metabolism: A Review. J Hematol Oncol (2019) 12:90. doi: 10.1186/s13045019-0776-8

20. Greene J, Baird AM, Brady L, Lim M, Gray SG, McDermott R, et al. Circular Rnas: Biogenesis, Function and Role in Human Diseases. Front Mol Biosci (2017) 4:38. doi: 10.3389/fmolb.2017.00038

21. Panni S, Lovering RC, Porras P, Orchard S. Non-Coding RNA Regulatory Networks. Biochim Biophys Acta Gene Regul Mech (2020) 1863:194417. doi: 10.1016/j.bbagrm.2019.194417

22. Salzman J, Gawad C, Wang PL, Lacayo N, Brown PO. Circular Rnas Are the Predominant Transcript Isoform From Hundreds of Human Genes in Diverse Cell Types. PloS One (2012) 7:e30733. doi: 10.1371/journal.pone.0030733

23. Memczak S, Jens M, Elefsinioti A, Torti F, Krueger J, Rybak A, et al. Circular RNAs Are a Large Class of Animal Rnas With Regulatory Potency. Nature (2013) 495:333-8. doi: 10.1038/nature11928

24. Li P, Chen S, Chen H, Mo X, Li T, Shao Y, et al. Using Circular RNA as a Novel Type of Biomarker in the Screening of Gastric Cancer. Clinica Chimica Acta; Int J Clin Chem (2015) 444:132-6. doi: 10.1016/j.cca.2015.02.018

25. Wilusz JE. Circular RNAs: Unexpected Outputs of Many Protein-Coding Genes. RNA Biol (2017) 14:1007-17. doi: 10.1080/15476286.2016.1227905

26. Ebbesen KK, Kjems J, Hansen TB. Circular RNAs: Identification, Biogenesis and Function. Biochim Biophys Acta (2016) 1859:163-8. doi: 10.1016/ j.bbagrm.2015.07.007

27. Sun J, Li B, Shu C, Ma Q, Wang J. Functions and Clinical Significance of Circular RNAs in Glioma. Mol Cancer (2020) 19:34. doi: 10.1186/s12943-019-1121-0

28. Goodall GJ, Wickramasinghe VO. RNA in Cancer. Nat Rev Cancer (2021) 21:22-36. doi: 10.1038/s41568-020-00306-0

29. Jeck WR, Sorrentino JA, Wang K, Slevin MK, Burd CE, Liu J, et al. Circular Rnas Are Abundant, Conserved, and Associated With ALU Repeats. RNA (New York NY) (2013) 19:141-57. doi: 10.1261/rna.035667.112
30. Zhang XO, Wang HB, Zhang Y, Lu X, Chen LL, Yang L. Complementary Sequence-Mediated Exon Circularization. Cell (2014) 159:134-47. doi: 10.1016/j.cell.2014.09.001

31. Zhou WY, Cai ZR, Liu J, Wang DS, Ju HQ, Xu RH. Circular RNA: Metabolism, Functions and Interactions With Proteins. Mol Cancer (2020) 19:172. doi: 10.1186/s12943-020-01286-3

32. Zhang HD, Jiang LH, Sun DW, Hou JC, Ji ZL. CircRNA: A Novel Type of Biomarker for Cancer. Breast Cancer (2018) 25:1-7. doi: 10.1007/s12282017-0793-9

33. Nair AA, Niu N, Tang X, Thompson KJ, Wang L, Kocher JP, et al. Circular Rnas and Their Associations With Breast Cancer Subtypes. Oncotarget (2016) 7:80967-79. doi: 10.18632/oncotarget.13134

34. Zang J, $\mathrm{Lu} \mathrm{D}, \mathrm{Xu}$ A. The Interaction of Circrnas and RNA Binding Proteins: An Important Part of Circrna Maintenance and Function. J Neurosci Res (2020) 98:87-97. doi: 10.1002/jnr.24356

35. Li Z, Huang C, Bao C, Chen L, Lin M, Wang X, et al. Exon-Intron Circular RNAs Regulate Transcription in the Nucleus. Nat Struct Mol Biol (2015) 22:256-64. doi: 10.1038/nsmb.2959

36. Lu Z, Filonov GS, Noto JJ, Schmidt CA, Hatkevich TL, Wen Y, et al. Metazoan tRNA Introns Generate Stable Circular Rnas In Vivo. RNA (New York NY) (2015) 21:1554-65. doi: 10.1261/rna.052944.115

37. Wang F, Nazarali AJ, Ji S. Circular RNAs as Potential Biomarkers for Cancer Diagnosis and Therapy. Am J Cancer Res (2016) 6:1167-76.

38. Schmidt CA, Giusto JD, Bao A, Hopper AK, Matera AG. Molecular Determinants of Metazoan Tricrna Biogenesis. Nucleic Acids Res (2019) 47:6452-65. doi: 10.1093/nar/gkz311

39. Suzuki H, Tsukahara T. A View of Pre-Mrna Splicing From Rnase R Resistant RNAs. Int J Mol Sci (2014) 15:9331-42. doi: 10.3390/ijms15069331

40. Wang PL, Bao Y, Yee MC, Barrett SP, Hogan GJ, Olsen MN, et al. Circular RNA Is Expressed Across the Eukaryotic Tree of Life. PloS One (2014) 9: e90859. doi: 10.1371/journal.pone.0090859

41. Rybak-Wolf A, Stottmeister C, Glažar P, Jens M, Pino N, Giusti S, et al. Circular Rnas in the Mammalian Brain Are Highly Abundant, Conserved, and Dynamically Expressed. Mol Cell (2015) 58:870-85. doi: 10.1016/ j.molcel.2015.03.027

42. Hansen TB, Jensen TI, Clausen BH, Bramsen JB, Finsen B, Damgaard CK, et al. Natural RNA Circles Function as Efficient Microrna Sponges. Nature (2013) 495:384-8. doi: 10.1038/nature11993

43. Du WW, Yang W, Liu E, Yang Z, Dhaliwal P, Yang BB. Foxo3 Circular RNA Retards Cell Cycle Progression via Forming Ternary Complexes With P21 and CDK2. Nucleic Acids Res (2016) 44:2846-58. doi: 10.1093/nar/gkw027

44. Legnini I, Di Timoteo G, Rossi F, Morlando M, Briganti F, Sthandier O, et al. Circ-ZNF609 Is a Circular RNA That can be Translated and Functions in Myogenesis. Mol Cell (2017) 66:22-37.e29. doi: 10.1016/j.molcel.2017.02.017

45. Lu D, Xu AD. Mini Review: Circular Rnas as Potential Clinical Biomarkers for Disorders in the Central Nervous System. Front Genet (2016) 7:53. doi: 10.3389/fgene.2016.00053

46. Zhang Y, Zhang XO, Chen T, Xiang JF, Yin QF, Xing YH, et al. Circular Intronic Long Noncoding Rnas. Mol Cell (2013) 51:792-806. doi: 10.1016/ j.molcel.2013.08.017

47. You X, Vlatkovic I, Babic A, Will T, Epstein I, Tushev G, et al. Neural Circular Rnas Are Derived From Synaptic Genes and Regulated by Development and Plasticity. Nat Neurosci (2015) 18:603-10. doi: 10.1038/nn.3975

48. Li J, Sun D, Pu W, Wang J, Peng Y. Circular Rnas in Cancer: Biogenesis, Function, and Clinical Significance. Trends Cancer (2020) 6:319-36. doi: 10.1016/j.trecan.2020.01.012

49. Wu P, Mo Y, Peng M, Tang T, Zhong Y, Deng X, et al. Emerging Role of Tumor-Related Functional Peptides Encoded by LncRNA and CircRNA. Mol Cancer (2020) 19:22. doi: 10.1186/s12943-020-1147-3

50. Jin D, Wu X, Yu H, Jiang L, Zhou P, Yao X, et al. Systematic Analysis of Lncrnas, Mrnas, Circrnas and Mirnas in Patients With Postmenopausal Osteoporosis. Am J Trans Res (2018) 10:1498-510.

51. Yang Y, Yujiao W, Fang W, Linhui Y, Ziqi G, Zhichen W, et al. The Roles of Mirna, Lncrna and Circrna in the Development of Osteoporosis. Biol Res (2020) 53:40. doi: 10.1186/s40659-020-00309-z

52. Kristensen LS, Andersen MS, Stagsted LVW, Ebbesen KK, Hansen TB, Kjems J. The Biogenesis, Biology and Characterization of Circular Rnas. Nat Rev Genet (2019) 20:675-91. doi: 10.1038/s41576-019-0158-7 
53. Lei M, Zheng G, Ning Q, Zheng J, Dong D. Translation and Functional Roles of Circular RNAs in Human Cancer. Mol Cancer (2020) 19:30. doi: 10.1186/ s12943-020-1135-7

54. Chen X, Yang T, Wang W, Xi W, Zhang T, Li Q, et al. Circular RNAs in Immune Responses and Immune Diseases. Theranostics (2019) 9:588-607. doi: 10.7150/thno.29678

55. Prats AC, David F, Diallo LH, Roussel E, Tatin F, Garmy-Susini B, et al. Circular RNA, the Key for Translation. Int J Mol Sci (2020) 21:8591. doi: $10.3390 /$ ijms 21228591

56. Hsiao KY, Lin YC, Gupta SK, Chang N, Yen L, Sun HS, et al. Noncoding Effects of Circular RNA CCDC66 Promote Colon Cancer Growth and Metastasis. Cancer Res (2017) 77:2339-50. doi: 10.1158/0008-5472.CAN16-1883

57. Han D, Li J, Wang H, Su X, Hou J, Gu Y, et al. Circular RNA Circmtol Acts as the Sponge of Microrna-9 to Suppress Hepatocellular Carcinoma Progression. Hepatol (Baltimore Md) (2017) 66:1151-64. doi: 10.1002/hep.29270

58. Barbagallo D, Caponnetto A, Brex D, Mirabella F, Barbagallo C, Lauretta G, et al. Circsmarca5 Regulates VEGFA Mrna Splicing and Angiogenesis in Glioblastoma Multiforme Through the Binding of SRSF1. Cancers (2019) 11:194. doi: 10.3390/cancers11020194

59. Pan H, Li T, Jiang Y, Pan C, Ding Y, Huang Z, et al. Overexpression of Circular RNA Cirs-7 Abrogates the Tumor Suppressive Effect of MiR-7 on Gastric Cancer via PTEN/PI3K/AKT Signaling Pathway. J Cell Biochem (2018) 119:440-6. doi: 10.1002/jcb.26201

60. Wang Y, Wang H, Zheng R, Wu P, Sun Z, Chen J, et al. Circular RNA ITCH Suppresses Metastasis of Gastric Cancer via Regulating MiR-199a-5p/Klotho Axis. Cell Cycle (Georgetown Tex) (2021) 20:522-36. doi: 10.1080/ 15384101.2021.1878327

61. Shang Q, Yang Z, Jia R, Ge S. The Novel Roles of CircRNAs in Human Cancer. Mol Cancer (2019) 18:6. doi: 10.1186/s12943-018-0934-6

62. Fang L, Du WW, Lyu J, Dong J, Zhang C, Yang W, et al. Enhanced Breast Cancer Progression by Mutant P53 Is Inhibited by the Circular RNA CircCcnb1. Cell Death Differ (2018) 25:2195-208. doi: 10.1038/s41418-0180115-6

63. He R, Liu P, Xie X, Zhou Y, Liao Q, Xiong W, et al. Circgfral and GFRA1 Act as Cernas in Triple Negative Breast Cancer by Regulating MiR-34a. J Exp Clin Cancer Res: CR (2017) 36:145. doi: 10.1186/s13046-017-0614-1

64. Dai X, Zhang N, Cheng Y, Yang T, Chen Y, Liu Z, et al. RNA-Binding Protein Trinucleotide Repeat-Containing 6A Regulates the Formation of Circular RNA Circ0006916, With Important Functions in Lung Cancer Cells. Carcinogenesis (2018) 39:981-92. doi: 10.1093/carcin/bgy061

65. Ojha R, Nandani R, Chatterjee N, Prajapati VK. Emerging Role of Circular Rnas as Potential Biomarkers for the Diagnosis of Human Diseases. Adv Exp Med Biol (2018) 1087:141-57. doi: 10.1007/978-981-13-1426-1_12

66. Qian Z, Liu H, Li M, Shi J, Li N, Zhang Y, et al. Potential Diagnostic Power of Blood Circular RNA Expression in Active Pulmonary Tuberculosis. EBioMedicine (2018) 27:18-26. doi: 10.1016/j.ebiom.2017.12.007

67. Wang M, Zhao J, Zhang L, Wei F, Lian Y, Wu Y, et al. Role of Tumor Microenvironment in Tumorigenesis. J Cancer (2017) 8:761-73. doi: $10.7150 /$ jca. 17648

68. Whiteside TL. The Tumor Microenvironment and Its Role in Promoting Tumor Growth. Oncogene (2008) 27:5904-12. doi: 10.1038/onc.2008.271

69. Wang J, De Veirman K, Faict S, Frassanito MA, Ribatti D, Vacca A, et al. Multiple Myeloma Exosomes Establish a Favourable Bone Marrow Microenvironment With Enhanced Angiogenesis and Immunosuppression. J Pathol (2016) 239:162-73. doi: 10.1002/path.4712

70. Li I, Nabet BY. Exosomes in the Tumor Microenvironment as Mediators of Cancer Therapy Resistance. Mol Cancer (2019) 18:32. doi: 10.1186/s12943019-0975-5

71. Mehla K, Singh PK. Metabolic Regulation of Macrophage Polarization in Cancer. Trends Cancer (2019) 5:822-34. doi: 10.1016/j.trecan.2019.10.007

72. Noy R, Pollard JW. Tumor-Associated Macrophages: From Mechanisms to Therapy. Immunity (2014) 41:49-61. doi: 10.1016/j.immuni.2014.06.010

73. Guerriero JL. Macrophages: The Road Less Traveled, Changing Anticancer Therapy. Trends Mol Med (2018) 24:472-89. doi: 10.1016/j.molmed.2018.03.006

74. De Palma M, Lewis CE. Macrophage Regulation of Tumor Responses to Anticancer Therapies. Cancer Cell (2013) 23:277-86. doi: 10.1016/ j.ccr.2013.02.013
75. Yan S, Wan G. Tumor-Associated Macrophages in Immunotherapy. FEBS J (2021) 288:6174-86. doi: 10.1111/febs.15726

76. Gonzalez H, Hagerling C, Werb Z. Roles of the Immune System in Cancer: From Tumor Initiation to Metastatic Progression. Genes Dev (2018) 32:1267-84. doi: $10.1101 /$ gad.314617.118

77. Ngambenjawong C, Gustafson HH, Pun SH. Progress in Tumor-Associated Macrophage (TAM)-Targeted Therapeutics. Adv Drug Deliv Rev (2017) 114:206-21. doi: 10.1016/j.addr.2017.04.010

78. Nimmerjahn F, Gordan S, Lux A. Fc $\gamma \mathrm{r}$ Dependent Mechanisms of Cytotoxic, Agonistic, and Neutralizing Antibody Activities. Trends Immunol (2015) 36:325-36. doi: 10.1016/j.it.2015.04.005

79. Andrade MR, Amaral EP, Ribeiro SC, Almeida FM, Peres TV, Lanes V, et al. Pathogenic Mycobacterium Bovis Strains Differ in Their Ability to Modulate the Proinflammatory Activation Phenotype of Macrophages. BMC Microbiol (2012) 12:166. doi: 10.1186/1471-2180-12-166

80. Nairz M, Schleicher U, Schroll A, Sonnweber T, Theurl I, Ludwiczek S, et al. Nitric Oxide-Mediated Regulation of Ferroportin-1 Controls Macrophage Iron Homeostasis and Immune Function in Salmonella Infection. J Exp Med (2013) 210:855-73. doi: 10.1084/jem.20121946

81. Podinovskaia M, Lee W, Caldwell S, Russell DG. Infection of Macrophages With Mycobacterium Tuberculosis Induces Global Modifications to Phagosomal Function. Cell Microbiol (2013) 15:843-59. doi: 10.1111/ cmi. 12092

82. Schliehe C, Redaelli C, Engelhardt S, Fehlings M, Mueller M, van Rooijen N, et al. CD8- Dendritic Cells and Macrophages Cross-Present Poly(D,LLactate-Co-Glycolate) Acid Microsphere-Encapsulated Antigen In Vivo. J Immunol (Baltimore Md: 1950) (2011) 187:2112-21. doi: 10.4049/ jimmunol.1002084

83. Abès R, Gélizé E, Fridman WH, Teillaud JL. Long-Lasting Antitumor Protection by Anti-CD20 Antibody Through Cellular Immune Response. Blood (2010) 116:926-34. doi: 10.1182/blood-2009-10-248609

84. Gül N, Babes L, Siegmund K, Korthouwer R, Bögels M, Braster R, et al. Macrophages Eliminate Circulating Tumor Cells After Monoclonal Antibody Therapy. J Clin Invest (2014) 124:812-23. doi: 10.1172/JCI66776

85. Anderson NR, Minutolo NG, Gill S, Klichinsky M. Macrophage-Based Approaches for Cancer Immunotherapy. Cancer Res (2021) 81:1201-8. doi: 10.1158/0008-5472.CAN-20-2990

86. Wynn TA, Chawla A, Pollard JW. Macrophage Biology in Development, Homeostasis and Disease. Nature (2013) 496:445-55. doi: 10.1038/ nature 12034

87. Ostuni R, Kratochvill F, Murray PJ, Natoli G. Macrophages and Cancer: From Mechanisms to Therapeutic Implications. Trends Immunol (2015) 36:229-39. doi: 10.1016/j.it.2015.02.004

88. Fu LQ, Du WL, Cai MH, Yao JY, Zhao YY, Mou XZ. The Roles of TumorAssociated Macrophages in Tumor Angiogenesis and Metastasis. Cell Immunol (2020) 353:104119. doi: 10.1016/j.cellimm.2020.104119

89. Movahedi K, Laoui D, Gysemans C, Baeten M, Stangé G, Van den Bossche J, et al. Different Tumor Microenvironments Contain Functionally Distinct Subsets of Macrophages Derived From Ly6C(High) Monocytes. Cancer Res (2010) 70:5728-39. doi: 10.1158/0008-5472.CAN-09-4672

90. Kes MMG, Van den Bossche J, Griffioen AW, Huijbers EJM. Oncometabolites Lactate and Succinate Drive Pro-Angiogenic Macrophage Response in Tumors. Biochim Biophys Acta Rev Cancer (2020) 1874:188427. doi: 10.1016/j.bbcan.2020.188427

91. Cassetta L, Pollard JW. Targeting Macrophages: Therapeutic Approaches in Cancer. Nat Rev Drug Discov (2018) 17:887-904. doi: 10.1038/nrd.2018.169

92. Varol C, Mildner A, Jung S. Macrophages: Development and Tissue Specialization. Annu Rev Immunol (2015) 33:643-75. doi: 10.1146/ annurev-immunol-032414-112220

93. Mantuano NR, Oliveira-Nunes MC, Alisson-Silva F, Dias WB, Todeschini AR. Emerging Role of Glycosylation in the Polarization of TumorAssociated Macrophages. Pharmacol Res (2019) 146:104285. doi: 10.1016/ j.phrs.2019.104285

94. Cortese N, Carriero R, Laghi L, Mantovani A, Marchesi F. Prognostic Significance of Tumor-Associated Macrophages: Past, Present and Future. Semin Immunol (2020) 48:101408. doi: 10.1016/j.smim.2020.101408

95. Grivennikov SI, Wang K, Mucida D, Stewart CA, Schnabl B, Jauch D, et al. Adenoma-Linked Barrier Defects and Microbial Products Drive IL-23/IL- 
17-Mediated Tumour Growth. Nature (2012) 491:254-8. doi: 10.1038/ nature 11465

96. Yang L, Zhang Y. Tumor-Associated Macrophages: From Basic Research to Clinical Application. J Hematol Oncol (2017) 10:58. doi: 10.1186/s13045017-0430-2

97. Yin M, LiX, Tan S, Zhou HJ, Ji W, Bellone S, et al. Tumor-Associated Macrophages Drive Spheroid Formation During Early Transcoelomic Metastasis of Ovarian Cancer. J Clin Invest (2016) 126:4157-73. doi: 10.1172/JCI87252

98. Pan Y, Yu Y, Wang X, Zhang T. Tumor-Associated Macrophages in Tumor Immunity. Front Immunol (2020) 11:583084. doi: 10.3389/fimmu.2020.583084

99. Yang Q, Guo N, Zhou Y, Chen J, Wei Q, Han M. The Role of TumorAssociated Macrophages (Tams) in Tumor Progression and Relevant Advance in Targeted Therapy. Acta Pharm Sin B (2020) 10:2156-70. doi: 10.1016/j.apsb.2020.04.004

100. Kim J, Bae JS. Tumor-Associated Macrophages and Neutrophils in Tumor Microenvironment. Mediators Inflamm (2016) 2016:6058147. doi: 10.1155/ 2016/6058147

101. Malekghasemi S, Majidi J, Baghbanzadeh A, Abdolalizadeh J, Baradaran B, Aghebati-Maleki L. Tumor-Associated Macrophages: Protumoral Macrophages in Inflammatory Tumor Microenvironment. Adv Pharm Bull (2020) 10:556-65. doi: 10.34172/apb.2020.066

102. Chávez-Galán L, Olleros ML, Vesin D, Garcia I. Much More Than M1 and M2 Macrophages, There Are Also CD169(+) and TCR(+) Macrophages. Front Immunol (2015) 6:263. doi: 10.3389/fimmu.2015.00263

103. Wang N, Wang S, Wang X, Zheng Y, Yang B, Zhang J, et al. Research Trends in Pharmacological Modulation of Tumor-Associated Macrophages. Clin Transl Med (2021) 11:e288. doi: 10.1002/ctm2.288

104. Cheng Y, Song S, Wu P, Lyu B, Qin M, Sun Y, et al. Tumor Associated Macrophages and Tams-Based Anti-Tumor Nanomedicines. Adv Healthc Mater (2021) 2021:e2100590. doi: 10.1002/adhm.202100590

105. Mukhtar RA, Nseyo O, Campbell MJ, Esserman LJ. Tumor-Associated Macrophages in Breast Cancer as Potential Biomarkers for New Treatments and Diagnostics. Expert Rev Mol Diagnostics (2011) 11:91-100. doi: 10.1586/erm.10.97

106. Pathria P, Louis TL, Varner JA. Targeting Tumor-Associated Macrophages in Cancer. Trends Immunol (2019) 40:310-27. doi: 10.1016/j.it.2019.02.003

107. Chen D, Zhang X, Li Z, Zhu B. Metabolic Regulatory Crosstalk Between Tumor Microenvironment and Tumor-Associated Macrophages. Theranostics (2021) 11:1016-30. doi: 10.7150/thno.51777

108. Hoves S, Ooi CH, Wolter C, Sade H, Bissinger S, Schmittnaegel M, et al. Rapid Activation of Tumor-Associated Macrophages Boosts Preexisting Tumor Immunity. J Exp Med (2018) 215:859-76. doi: 10.1084/jem.20171440

109. Zhou K, Cheng T, Zhan J, Peng X, Zhang Y, Wen J, et al. Targeting TumorAssociated Macrophages in the Tumor Microenvironment. Oncol Lett (2020) 20:234. doi: 10.3892/ol.2020.12097

110. Long KB, Collier AI, Beatty GL. Macrophages: Key Orchestrators of a Tumor Microenvironment Defined by Therapeutic Resistance. Mol Immunol (2019) 110:3-12. doi: 10.1016/j.molimm.2017.12.003

111. Mantovani A, Marchesi F, Malesci A, Laghi L, Allavena P. TumourAssociated Macrophages as Treatment Targets in Oncology. Nat Rev Clin Oncol (2017) 14:399-416. doi: 10.1038/nrclinonc.2016.217

112. Yang M, McKay D, Pollard JW, Lewis CE. Diverse Functions of Macrophages in Different Tumor Microenvironments. Cancer Res (2018) 78:5492-503. doi: 10.1158/0008-5472.CAN-18-1367

113. Chen C, Liu JM, Luo YP. MicroRNAs in Tumor Immunity: Functional Regulation in Tumor-Associated Macrophages. J Zhejiang Univ Sci B (2020) 21:12-28. doi: 10.1631/jzus.B1900452

114. Myers KV, Amend SR, Pienta KJ. Targeting Tyro3, Axl and Mertk (TAM Receptors): Implications for Macrophages in the Tumor Microenvironment. Mol Cancer (2019) 18:94. doi: 10.1186/s12943-019-1022-2

115. Vesely MD, Kershaw MH, Schreiber RD, Smyth MJ. Natural Innate and Adaptive Immunity to Cancer. Annu Rev Immunol (2011) 29:235-71. doi: 10.1146/annurev-immunol-031210-101324

116. Li X, Yao W, Yuan Y, Chen P, Li B, Li J, et al. Targeting of TumourInfiltrating Macrophages via CCL2/CCR2 Signalling as a Therapeutic Strategy Against Hepatocellular Carcinoma. Gut (2017) 66:157-67. doi: 10.1136/gutjnl-2015-310514
117. Hu ZQ, Zhou SL, Li J, Zhou ZJ, Wang PC, Xin HY, et al. Circular RNA Sequencing Identifies Circasap1 as a Key Regulator in Hepatocellular Carcinoma Metastasis. Hepatol (Baltimore Md) (2020) 72:906-22. doi: 10.1002/hep.31068

118. Shuai K, Stark GR, Kerr IM, Darnell JE Jr. a Single Phosphotyrosine Residue of Stat91 Required for Gene Activation by Interferon-Gamma. Sci (New York NY) (1993) 261:1744-6. doi: 10.1126/science.7690989

119. Zhong Z, Wen Z, Darnell JEJr. Stat3: A STAT Family Member Activated by Tyrosine Phosphorylation in Response to Epidermal Growth Factor and Interleukin-6. Sci (New York NY) (1994) 264:95-8. doi: 10.1126/ science. 8140422

120. Toshchakov V, Jones BW, Perera PY, Thomas K, Cody MJ, Zhang S, et al. TLR4, But Not TLR2, Mediates IFN-Beta-Induced STAT1alpha/BetaDependent Gene Expression in Macrophages. Nat Immunol (2002) 3:3928. doi: $10.1038 /$ ni774

121. Zhang C, Han X, Yang L, Fu J, Sun C, Huang S, et al. Circular RNA Circppm1f Modulates M1 Macrophage Activation and Pancreatic Islet Inflammation in Type 1 Diabetes Mellitus. Theranostics (2020) 10:1090824. doi: 10.7150/thno.48264

122. Song H, Yang Y, Sun Y, Wei G, Zheng H, Chen Y, et al. Circular RNA Cdyl Promotes Abdominal Aortic Aneurysm Formation by Inducing M1 Macrophage Polarization and M1-Type Inflammation. Mol therapy: J Am Soc Gene Ther (2021) S1525-0016(21):00472-X. doi: 10.1016/j.ymthe. 2021.09.017

123. Jenkins SJ, Ruckerl D, Thomas GD, Hewitson JP, Duncan S, Brombacher F, et al. IL-4 Directly Signals Tissue-Resident Macrophages to Proliferate Beyond Homeostatic Levels Controlled by CSF-1. J Exp Med (2013) 210:2477-91. doi: 10.1084/jem.20121999

124. Murray PJ, Allen JE, Biswas SK, Fisher EA, Gilroy DW, Goerdt S, et al. Macrophage Activation and Polarization: Nomenclature and Experimental Guidelines. Immunity (2014) 41:14-20. doi: 10.1016/j.immuni.2014.06.008

125. Zhang J, Cheng F, Rong G, Tang Z, Gui B. Circular RNA Hsa_Circ_0005567 Overexpression Promotes M2 Type Macrophage Polarization Through Mir492/SOCS2 Axis to Inhibit Osteoarthritis Progression. Bioengineered (2021) 12(1):8920-30. doi: 10.1080/21655979.2021.1989999

126. Zhang Y, Zhang Y, Li X, Zhang M, Lv K. Microarray Analysis of Circular RNA Expression Patterns in Polarized Macrophages. Int J Mol Med (2017) 39:373-9. doi: 10.3892/ijmm.2017.2852

127. Zhu S, Guo Y, Zhang X, Liu H, Yin M, Chen X, et al. Pyruvate Kinase M2 (PKM2) in Cancer and Cancer Therapeutics. Cancer Lett (2021) 503:240-8. doi: 10.1016/j.canlet.2020.11.018

128. Lu Q, Wang X, Zhu J, Fei X, Chen H, Li C. Hypoxic Tumor-Derived Exosomal Circ0048117 Facilitates M2 Macrophage Polarization Acting as MiR-140 Sponge in Esophageal Squamous Cell Carcinoma. OncoTargets Ther (2020) 13:11883-97. doi: 10.2147/OTT.S284192

129. Liu WT, Jing YY, Yu GF, Han ZP, Yu DD, Fan QM, et al. Toll Like Receptor 4 Facilitates Invasion and Migration as a Cancer Stem Cell Marker in Hepatocellular Carcinoma. Cancer Lett (2015) 358:136-43. doi: 10.1016/ j.canlet.2014.12.019

130. Huang Z, Yao F, Liu J, Xu J, Guo Y, Su R, et al. Up-Regulation of CircRNA0003528 Promotes Mycobacterium Tuberculosis Associated Macrophage Polarization via Down-Regulating Mir-224-5p, MiR-324-5p and MiR-4885p and Up-Regulating CTLA4. Aging (2020) 12:25658-72. doi: 10.18632/ aging. 104175

131. Lasda E, Parker R. Circular RNAs Co-Precipitate With Extracellular Vesicles: A Possible Mechanism for CircRNA Clearance. PloS One (2016) 11: e0148407. doi: 10.1371/journal.pone.0148407

132. Li P, Liu C, Yu Z, Wu M. New Insights Into Regulatory T Cells: Exosomeand Non-Coding RNA-Mediated Regulation of Homeostasis and Resident Treg Cells. Front Immunol (2016) 7:574. doi: 10.3389/fimmu.2016.00574

133. Ouyang W, O'Garra A. IL-10 Family Cytokines IL-10 and IL-22: From Basic Science to Clinical Translation. Immunity (2019) 50:871-91. doi: 10.1016/ j.immuni.2019.03.020

134. Sarode P, Zheng X, Giotopoulou GA, Weigert A, Kuenne C, Günther S, et al. Reprogramming of Tumor-Associated Macrophages by Targeting $\beta$ Catenin/FOSL2/ARID5A Signaling: A Potential Treatment of Lung Cancer. Sci $A d v$ (2020) 6:eaaz6105. doi: 10.1126/sciadv.aaz6105 
135. Liu YC, Zou XB, Chai YF, Yao YM. Macrophage Polarization in Inflammatory Diseases. Int J Biol Sci (2014) 10:520-9. doi: 10.7150/ijbs.8879

136. Mantovani A, Germano G, Marchesi F, Locatelli M, Biswas SK. CancerPromoting Tumor-Associated Macrophages: New Vistas and Open Questions. Eur J Immunol (2011) 41:2522-5. doi: 10.1002/eji.201141894

137. Ma Z, Shuai Y, Gao X, Wen X, Ji J. Circular RNAs in the Tumour Microenvironment. Mol Cancer (2020) 19:8. doi: 10.1186/s12943-019-1113-0

138. Zhong Z, Huang M, Lv M, He Y, Duan C, Zhang L, et al. Circular RNA MYLK as a Competing Endogenous RNA Promotes Bladder Cancer Progression Through Modulating VEGFA/VEGFR2 Signaling Pathway. Cancer Lett (2017) 403:305-17. doi: 10.1016/j.canlet.2017.06.027

139. Li CY, Ma L, Yu B. Circular RNA Hsa_Circ_0003575 Regulates Oxldl Induced Vascular Endothelial Cells Proliferation and Angiogenesis. Biomed Pharmacother (2017) 95:1514-9. doi: 10.1016/j.biopha.2017.09.064

140. Kugeratski FG, Atkinson SJ, Neilson LJ, Lilla S, Knight JRP, Serneels J, et al. Hypoxic Cancer-Associated Fibroblasts Increase NCBP2-AS2/HIAR to Promote Endothelial Sprouting Through Enhanced VEGF Signaling. Sci Signal (2019) 12:eaan8247. doi: 10.1126/scisignal.aan8247

141. Li X, Liu CX, Xue W, Zhang Y, Jiang S, Yin QF, et al. Coordinated CircRNA Biogenesis and Function With NF90/NF110 in Viral Infection. Mol Cell (2017) 67:214-27.e217. doi: 10.1016/j.molcel.2017.05.023

142. Wang M, Yu F, Wu W, Zhang Y, Chang W, Ponnusamy M, et al. Circular RNAs: A Novel Type of Non-Coding RNA and Their Potential Implications in Antiviral Immunity. Int J Biol Sci (2017) 13:1497-506. doi: 10.7150/ijbs.22531

143. Li J, Li Z, Jiang P, Peng M, Zhang X, Chen K, et al. Circular RNA IARS (CircIARS) Secreted by Pancreatic Cancer Cells and Located Within Exosomes Regulates Endothelial Monolayer Permeability to Promote Tumor Metastasis. J Exp Clin Cancer Res: CR (2018) 37:177. doi: 10.1186/s13046018-0822-3

144. Zhang XL, Xu LL, Wang F. Hsa_Circ_0020397 Regulates Colorectal Cancer Cell Viability, Apoptosis and Invasion by Promoting the Expression of the MiR-138 Targets TERT and PD-L1. Cell Biol Int (2017) 41:1056-64. doi: 10.1002/cbin.10826

145. Lankadasari MB, Mukhopadhyay P, Mohammed S, Harikumar KB. Taming Pancreatic Cancer: Combat With a Double Edged Sword. Mol Cancer (2019) 18:48. doi: 10.1186/s12943-019-0966-6

146. Lewis CE, Pollard JW. Distinct Role of Macrophages in Different Tumor Microenvironments. Cancer Res (2006) 66:605-12. doi: 10.1158/00085472.CAN-05-4005

147. Katopodi T, Petanidis S, Domvri K, Zarogoulidis P, Anestakis D, Charalampidis C, et al. Kras-Driven Intratumoral Heterogeneity Triggers Infiltration of M2 Polarized Macrophages via the Circhipk3/PTK2 Immunosuppressive Circuit. Sci Rep (2021) 11:15455. doi: 10.1038/s41598-021-94671-x

148. Lobb RJ, Lima LG, Möller A. Exosomes: Key Mediators of Metastasis and Pre-Metastatic Niche Formation. Semin Cell Dev Biol (2017) 67:3-10. doi: 10.1016/j.semcdb.2017.01.004

149. Zhang L, Zhang S, Yao J, Lowery FJ, Zhang Q, Huang WC, et al. Microenvironment-Induced PTEN Loss by Exosomal MicroRNA Primes Brain Metastasis Outgrowth. Nature (2015) 527:100-4. doi: 10.1038/nature15376

150. Wang X, Sheng W, Xu T, Xu J, Gao R, Zhang Z. CircRNA Hsa_Circ_0110102 Inhibited Macrophage Activation and Hepatocellular Carcinoma Progression via MiR-580-5p/Pparo/CCL2 Pathway. Aging (2021) 13:11969-87. doi: 10.18632/aging.202900

151. Lan J, Sun L, Xu F, Liu L, Hu F, Song D, et al. M2 Macrophage-Derived Exosomes Promote Cell Migration and Invasion in Colon Cancer. Cancer Res (2019) 79:146-58. doi: 10.1158/0008-5472.CAN-18-0014
152. Qiu L, Xu H, Ji M, Shang D, Lu Z, Wu Y, et al. Circular Rnas in Hepatocellular Carcinoma: Biomarkers, Functions and Mechanisms. Life Sci (2019) 231:116660. doi: 10.1016/j.lfs.2019.116660

153. Zhang QW, Liu L, Gong CY, Shi HS, Zeng YH, Wang XZ, et al. Prognostic Significance of Tumor-Associated Macrophages in Solid Tumor: A MetaAnalysis of the Literature. PloS One (2012) 7:e50946. doi: 10.1371/ journal.pone.0050946

154. Xu ZQ, Yang MG, Liu HJ, Su CQ. Circular RNA Hsa_Circ_0003221 (Circptk2) Promotes the Proliferation and Migration of Bladder Cancer Cells. J Cell Biochem (2018) 119:3317-25. doi: 10.1002/jcb.26492

155. Zhang Y, Li C, Liu X, Wang Y, Zhao R, Yang Y, et al. Circhipk3 Promotes Oxaliplatin-Resistance in Colorectal Cancer Through Autophagy by Sponging MiR-637. EBioMedicine (2019) 48:277-88. doi: 10.1016/ j.ebiom.2019.09.051

156. Wang J, Zhao X, Wang Y, Ren F, Sun D, Yan Y, et al. CircRNA-002178 Act as a Cerna to Promote PDL1/PD1 Expression in Lung Adenocarcinoma. Cell Death Dis (2020) 11:32. doi: 10.1038/s41419-020-2230-9

157. Cooks T, Pateras IS, Jenkins LM, Patel KM, Robles AI, Morris J, et al. Mutant P53 Cancers Reprogram Macrophages to Tumor Supporting Macrophages via Exosomal MiR-1246. Nat Commun (2018) 9:771. doi: 10.1038/s41467018-03224-w

158. Shang A, Gu C, Wang W, Wang X, Sun J, Zeng B, et al. Exosomal Circpacrgl Promotes Progression of Colorectal Cancer via the MiR-142-3p/MiR-506-3pTGF- $\beta 1$ Axis. Mol Cancer (2020) 19:117. doi: 10.1186/s12943-020-01235-0

159. Yu Y, Bian L, Liu R, Wang Y, Xiao X. Circular RNA Hsa_Circ_0061395 Accelerates Hepatocellular Carcinoma Progression via Regulation of the MiR-877-5p/PIK3R3 Axis. Cancer Cell Int (2021) 21:10. doi: 10.1186/ s12935-020-01695-w

160. Lyu P, Zhai Z, Hao Z, Zhang H, He J. Circwhsc1 Serves as an Oncogene to Promote Hepatocellular Carcinoma Progression. Eur J Clin Invest (2021) 51: e13487. doi: 10.1111/eci.13487

161. Sun G, Li Z, He Z, Wang W, Wang S, Zhang X, et al. Circular RNA MCTP2 Inhibits Cisplatin Resistance in Gastric Cancer by Mir-99a-5p-Mediated Induction of MTMR3 Expression. J Exp Clin Cancer Research: CR (2020) 39:246. doi: 10.1186/s13046-020-01758-w

162. Zhang H, Deng T, Ge S, Liu Y, Bai M, Zhu K, et al. Exosome Circrna Secreted From Adipocytes Promotes the Growth of Hepatocellular Carcinoma by Targeting Deubiquitination-Related USP7. Oncogene (2019) 38:2844-59. doi: $10.1038 / \mathrm{s} 41388-018-0619-\mathrm{z}$

Conflict of Interest: The authors declare that the research was conducted in the absence of any commercial or financial relationships that could be construed as a potential conflict of interest.

Publisher's Note: All claims expressed in this article are solely those of the authors and do not necessarily represent those of their affiliated organizations, or those of the publisher, the editors and the reviewers. Any product that may be evaluated in this article, or claim that may be made by its manufacturer, is not guaranteed or endorsed by the publisher.

Copyright (c) 2021 Duan, Wang, Huang, Wang and Yuan. This is an open-access article distributed under the terms of the Creative Commons Attribution License (CC BY). The use, distribution or reproduction in other forums is permitted, provided the original author(s) and the copyright owner(s) are credited and that the original publication in this journal is cited, in accordance with accepted academic practice. No use, distribution or reproduction is permitted which does not comply with these terms. 